\title{
Parasites of vectors - Ixodiphagus hookeri and its Wolbachia symbionts in ticks in the Netherlands
}

\author{
Ellen Tijsse-Klasen ${ }^{1}$, Marieta Braks ${ }^{1}$, Ernst-Jan Scholte ${ }^{2}$ and Hein Sprong ${ }^{1 *}$
}

\begin{abstract}
Background: Ixodiphagus hookeri is a parasitic wasp of ixodid ticks around the world. It has been studied as a potential bio-control agent for several tick species. We suspected that the presence of Wolbachia infected I. hookeri eggs in ticks is responsible for incidental detection of Wolbachia DNA in tick samples.

Methods: The $28 S$ rRNA and 165 rRNA genes of a specimen of I. hookeri was amplified and sequenced. PCR on part of the $28 \mathrm{~S}$ rRNA gene was used to detect parasitic wasp DNA in 349 questing /xodes ricinus ticks from various sampling sites. Furthermore, the wsp gene of Wolbachia was sequenced from the I. hookeri specimen and a subset of ticks was tested using this marker.
\end{abstract}

Results: Several sequences from tick specimens were identical to the Wolbachia sequence of the I. hookeri specimen. Ixodiphagus hookeri was detected in $9.5 \%$ of all tested ticks, varying between $4 \%$ and $26 \%$ depending on geographic location. Ten out of eleven sampling sites throughout the Netherlands were positive for $I$. hookeri. Eighty-seven percent of I. hookeri-positive but only $1.6 \%$ of I. hookeri-negative ticks were Wolbachia positive. Detection of I. hookeri DNA was strongly associated with the detection of Wolbachia in ticks.

Conclusion: This is the first reported case of I. hookeri in the Netherlands. Furthermore I. hookeri harbours Wolbachia species and is broadly distributed in the Netherlands. While detection of Wolbachia DNA in ticks might often be due to parasitism with this wasp, other sources of Wolbachia DNA in ticks might exist as well.

Keywords: Ixodiphagus hookeri, Ixodes ricinus, Parasitic wasp, Tick, Wolbachia

\section{Background}

Ticks as vectors for disease

Ticks carry numerous microorganisms, ranging from highly pathogenic bacteria to intracellular symbionts. In addition to well-known pathogens including Rickettsia spp., Borrelia burgdorferi s.l. and Anaplasma spp., more and more tick-associated bacteria are discovered with molecular techniques. Initially, the role of such microorganisms for the tick or in the context of public health remains unknown. Several examples can be named here, ranging from probable endosymbionts of ticks like 'Candidatus Midichloria mitochondrii' to 'Candidatus Neoehrlichia mikurensis' which was found recently to be involved in several cases of severe human disease [1-9].

\footnotetext{
* Correspondence: Hein.Sprong@rivm.nl

'Laboratory for Zoonoses and Environmental Microbiology, National Institute for Public Health and Environment (RIVM), Bilthoven, The Netherlands Full list of author information is available at the end of the article
}

Wolbachia in insects and its unclear role in ticks Bacteria belonging to the group of Wolbachia pipientis have been detected in several studies in Ixodes ricinus ticks [10-13]. Bacteria from this group are known endosymbionts from a high variety of insects, mites and nematodes. They act, depending on the Wolbachia strain and host species, as mutualistic, commensalistic or parasitic symbionts [14-16]. Wolbachia have been shown to influence the reproduction of infected insects in various ways, including parthenogenesis, male killing, cytoplasmic incompatibility and feminization [16]. So far, the role of Wolbachia in ticks remained unclear $[10,13]$. Its prevalence was usually too low to be explained by obligatory symbiosis and it remained unclear how the ticks became infected. In the current study we offer an explanation for the source of Wolbachia sequences amplified from ticks.

\section{Biomed Central}




\section{Ixodiphagus hookeri}

Unexpectedly, three wasps hatched in our laboratory from an engorged nymphal $I$. ricinus tick. In accordance with the origin of the wasps we suspected these to be Ixodiphagus hookeri (Howard), a parasitoid of ticks belonging to the order Hymenoptera and the family Encyrtidae. I. hookeri is known to occur on all continents except for Antarctica and to infest various tick species [17]. So far, it had not been reported from the Netherlands.

Mating of $I$. hookeri occurs shortly after emerging from their tick host [15]. Females then search for a suitable tick host and oviposit several eggs per tick, for I. ricinus up to 15 wasps per nymph have been observed [18]. In a European setting unfed nymphs of $I$. ricinus are preferred above $I$. ricinus larvae and fed nymphs [18]. Worldwide at least 14 ixodid tick species, including several Ixodes spp., have been found to be suitable hosts. Suitability, however, might depend on the I. hookeri strain [17-19]. I. hookeri has been investigated for its potential as biological tick control agent with variable results $[17,20]$.

\section{Study question}

The discovery of parasitic wasps in Dutch ticks led to the suspicion that Wolbachia sequences from ticks previously identified in our laboratory and reported from other studies $[10,12,13,21]$ might in fact be due to Wolbachia endosymbionts of tick parasitoids. We tested this by initially testing the parasitic wasp for Wolbachia. Ticks were examined for the presence of parasitoid DNA and Wolbachia by PCR to investigate associations between these two parameters. Additionally, the prevalence and distribution of $I$. hookeri in the Netherlands was investigated by testing ticks from various sites throughout the country.

\section{Methods}

\section{Ixodiphagus source}

Three specimens of parasitic wasp hatched from an engorged $I$. ricinus nymph that had been collected from sheep in a nature reserve area in the south-west of the Netherlands on September $7^{\text {th }}, 2010$. Ticks had been pooled per sheep and stored in $50 \mathrm{ml}$ polypropylene tubes at room temperature, approximately $80 \%$ relative humidity and a natural day/night cycle. The parasitic wasps hatched between October 2010 and January 2011 and were discovered on January $10^{\text {th }}, 2011$. Two specimens were sent to the Natural History Museum, London, for taxonomic determination while the third specimen remained in our laboratory for molecular investigations. Total DNA was extracted from one specimen by alkaline lysis as described elsewhere [2].

\section{Ticks tested}

Pilot test: From several studies from recent years (20082010) 27 Wolbachia positive ticks tested by reverse line blot (RLB) (as described in [12,22]) were selected. Additionally, one Wolbachia negative tick from the matching study was selected for each positive tick. In order to determine the distribution and prevalence of $I$. hookeri in the Netherlands adult and nymphal ticks from eleven different locations across the Netherlands were tested. Depending on availability, between 19 and 48 ticks per location were tested (for one location only 3 ticks were available). Total DNA was extracted from the ticks by alkaline lysis as described elsewhere [2].

\section{PCR Ixodiphagus}

Several primer pairs (Table 1) targeting the $16 \mathrm{~S}$ rRNA or 28S $r R N A$ genes were tested on DNA extracted from an $I$. hookeri (Howard) specimen. As a positive control, DNA of Vespula vulgaris was used. PCR products were analyzed on agarose gels. All primer pairs yielded bands for $V$. vulgaris DNA and all but the 16S-F1/16S-R1 combination yielded PCR products for I. hookeri (Howard).

Ticks from the pilot study were tested for the presence of Hymenoptera DNA by amplification of part of the $28 \mathrm{~S}$ rRNA gene using primer pair 28S-F1/28S-R1 and part of the $16 \mathrm{~S} r R N A$ gene using primer pair $16 \mathrm{~S}-\mathrm{F} 2 / 16 \mathrm{~S}-\mathrm{R} 1$. Ticks from the prevalence study were tested with primer pair 28S-F1/28S-R1.

PCR was done using HotStarTaq master mix (Qiagen, Germany) with the following conditions: $15 \mathrm{~min}$ at $95^{\circ} \mathrm{C}$, then cycles of $30 \mathrm{~s}$ at $94^{\circ} \mathrm{C}, 30 \mathrm{~s}$ at $65^{\circ} \mathrm{C}, 60 \mathrm{~s}$ at $72^{\circ} \mathrm{C}$, lowering the annealing temperature by $1^{\circ} \mathrm{C}$ each cycle until reaching $55^{\circ} \mathrm{C}$, then 35 cycles at this annealing temperature followed by a final elongation step for $7 \mathrm{~min}$ at $72^{\circ} \mathrm{C}$. Samples were analyzed on agarose gels.

\section{PCR Wolbachia}

DNA of the I. hookeri specimen and ticks were tested for the presence of Wolbachia DNA by amplification of part of the $w s p$ gene using primer pair wsp81F/wsp691R (Table 2) [23]. PCR was done using HotStarTaq master mix (Qiagen, Germany) with the touch down PCR protocol as described above with a starting annealing temperature of $60^{\circ} \mathrm{C}$ and a final annealing temperature of $50^{\circ} \mathrm{C}$.

\section{Sequencing}

PCR products were sequenced using an ABI PRISM BigDye Terminator Cycle sequencing Ready Reaction kit (Perkin Elmer, Applied Biosystems). All sequences were confirmed by sequencing both strands.

Sequencing of the Wolbachia wsp gene indicated double infections with Wolbachia in some tick samples and for these specimens additional sequencing primers were used (wspF2a, wspF2b, wspR2a, wspR2b) (Table 2).

Resulting sequences were compared with sequences in Genbank using BLAST. 
Table 1 Primers used for amplification and sequencing of Ixodiphagus hookeri (Howard) DNA

\begin{tabular}{|c|c|c|c|c|}
\hline Primer & Target & sequence $5^{\prime} \rightarrow 3^{\prime}$ & original name & Reference \\
\hline $16 \mathrm{~S}-\mathrm{F1}$ & $16 \mathrm{~S}$ rRNA & cacctgtttatcaaaaacat & $16 \mathrm{SWb}$ & {$[32]$} \\
\hline $16 \mathrm{~S}-\mathrm{F} 2$ & $16 \mathrm{~S}$ rRNA & ctgcagtattttgactgtacaaaggtagcataatc & - & This study \\
\hline $16 \mathrm{~S}-\mathrm{R} 1$ & $16 \mathrm{~S}$ rRNA & cttaattcaacatcgaggtcgc & - & modified from [33] \\
\hline 28S-F1 & $28 \mathrm{~S}$ rRNA & aagagagagttcaagagtacgtg & - & {$[34]$} \\
\hline $28 \mathrm{~S}-\mathrm{F} 2$ & $28 \mathrm{~S}$ rRNA & actttcaggacccgtcttga & - & $\mathrm{R} / \mathrm{C}$ of $28 \mathrm{~S}-\mathrm{R} 1$ \\
\hline $28 \mathrm{~S}-\mathrm{R} 1$ & $28 \mathrm{~S}$ rRNA & tcaagacgggtcctgaaagt & D2-4057 R & [35] \\
\hline $28 \mathrm{~S}-\mathrm{R} 2$ & $28 \mathrm{~S}$ rRNA & tagttcaccatctttcgggtccc & 28S-PM & [34] \\
\hline 28S-R3 & $28 \mathrm{~S}$ rRNA & tcggaaggaaccagctacta & D3-4413 R & [35] \\
\hline
\end{tabular}

$\mathrm{R} / \mathrm{C}$ : reverse-complement

\section{Statistical analysis}

Positive and negative predictive values with regard to Wolbachia wsp PCR results as predictors for a positive and negative PCR results for Hymenoptera DNA were calculated. Additionally the significance of the association between these two PCRs was tested using Mid-P exact test [24].

\section{Results}

Identification of parasitic wasps

The collected parasitic wasps were morphologically identified as Ixodiphagus hookeri (Howard) by John Noyes at the Natural History Museum, London (Figure 1). This species had previously not been reported from the Netherlands and has in the meantime been added to the list of Dutch Chalcidoidea and the Dutch Species Catalogue [25].

\section{PCR on Ixodiphagus hookeri}

The 28S rRNA and 16S rRNA genes of I. hookeri were successfully amplified and sequenced. After clipping off the primer sites, sequences of $824 \mathrm{bp}$ and 318 bp were obtained, respectively. BLASTing of the $28 \mathrm{~S} r R N A$ and $16 \mathrm{~S} r R N A$ sequences gave closest matches with the hymenopteran parasitoids Plagiomerus diaspidis (accession code AY599316, 84\% identity) and Cotesia flaviconchae (AJ535921, 80\% identity, 89\% coverage), respectively.

Sequencing of the Wolbachia wsp gene yielded a sequence of 573 bp with no indications of double infection. BLASTing of the wsp sequence gave close matches with a number of Wolbachia endosymbionts of various insects. A phylogenetic tree based on the wsp gene was calculated (Figure 2).

\section{Pilot study}

Fifty-four ticks were tested for the presence of I. hookeri and Wolbachia DNA. Amplification of the 16S rRNA gene yielded unspecific products, which were not used for further analysis. Amplified products of 28S $r R N A$ and wsp genes were sequenced. Most RLB Wolbachia-positive ticks were positive for $28 \mathrm{~S} r R N A$ as well as $w s p$ genes. Five ticks of this group were positive for the $w s p$ gene but delivered no or divergent $28 \mathrm{~S}$ rRNA sequences. One tick was $I$. hookeri positive but did not produce a wsp amplification product. Four RLB Wolbachia-positive ticks were negative for either PCR. Twenty-four of 27 ticks from the RLB Wolbachia-negative control group yielded no PCR products for either 28S rRNA or wsp genes. Two ticks yielded $28 \mathrm{~S} r R N A$ sequences different from $I$. hookeri and one tick yielded a wsp sequence different from the I. hookeri isolate. Wolbachia wsp sequences from several $I$. hookeri positive ticks failed to be sequenced in adequate length and quality, which was apparently due to double infection with multiple Wolbachia strains.

\section{Prevalence study}

A total of 341 ticks were tested for the presence of $I$. hookeri PCR amplification of the 28S rRNA gene. Additionally 143 of these ticks were tested for Wolbachia by amplification of the wsp gene. Ixodiphagus hookeri DNA was detected in $9.7 \%(n=33)$ of all ticks. Ten of eleven locations were found positive with a prevalence ranging from $4 \%$ to $26 \%$ (Figure 3 and 4 ). For the remaining site only 3 ticks were available, which were all negative. Of the 143 ticks tested for Wolbachia, 10.5\% ( $\mathrm{n}=15)$ were

Table 2 Primers used for amplification and sequencing of Wolbachia DNA

\begin{tabular}{|c|c|c|c|c|}
\hline Primer & Target & sequence $5^{\prime} \rightarrow 3^{\prime}$ & original name & Reference \\
\hline wsp $81 \mathrm{~F}$ & wsp gene & tggtccaataagtgatgaagaaac & wsp $81 F$ & {$[23]$} \\
\hline wsp 691R & wsp gene & aaaaattaaacgctactcca & wsp 691R & {$[23]$} \\
\hline wspF2a & wsp gene & aaggccacagacattcataatccattaaaagcatc & - & This study \\
\hline wspF2b & wsp gene & gcaacaggcaaagaaaaggatagtccct & - & This study \\
\hline wspR2a & wsp gene & acagtgctgtaaaggactgtatgtcctcctttg & - & This study \\
\hline wspR2b & wsp gene & acagtgctgtaaaggactgtatgtcctcctttg & - & This study \\
\hline
\end{tabular}



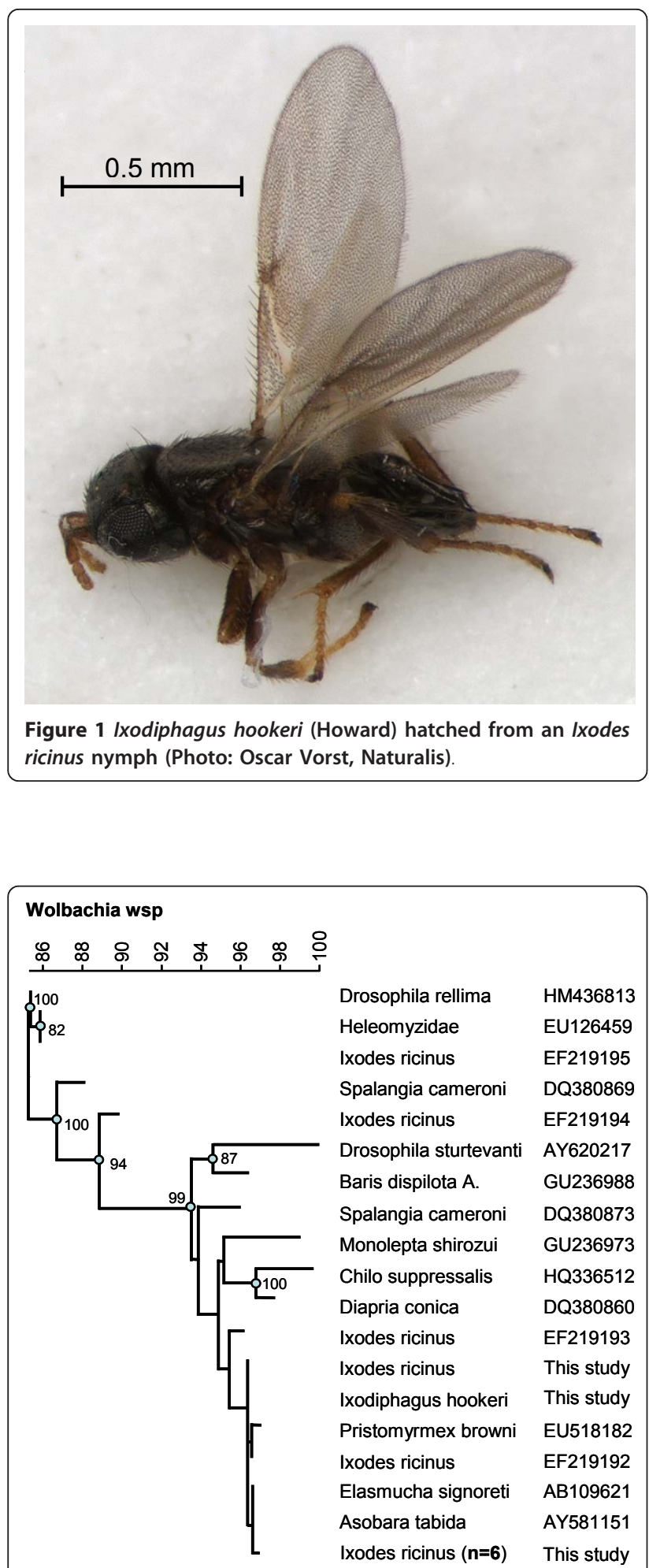

Figure 2 Phylogenetic analysis of Wolbachia from various invertebrate host species. Neighbor-joining trees with Kimura correction were based on wsp genes from this study and mined from GeneBank. Bootstrap proportions were calculated based on 500 replicates, only values $<80$ are indicated.

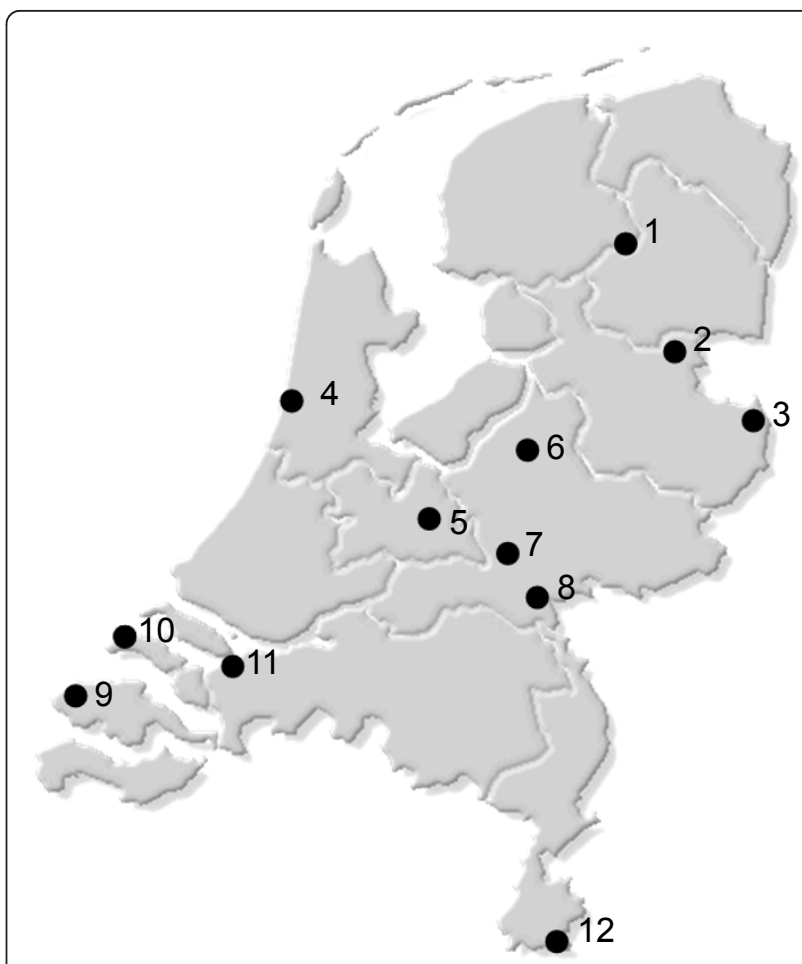

Figure 3 Locations in the Netherlands with PCR verified presence of Ixodiphagus hookeri infested Ixodes ricinus ticks. Drents-Friese Wold; 2. Boswachterij Hardenberg; 3. Landgoed Singraven; 4. Duin en Kruidberg; 5. Pyramide van Austerlitz; 6. Koninklijke Houtvesterijen Hoog Soeren; 7. Hullenberg; 8. Rijk van Nijmegen; 9. Kop van Schouwen; 10. Vrouwenpolder; 11. Dintelse Gorzen; 12. Vijlenerbos; Two of these sites (7 and 10) were found positive in the pilot study; the remaining sites were investigated in the prevalence study.

found positive (Table 3). Two ticks that had been found positive for I. hookeri DNA were negative for Wolbachia and vice versa. A tick positive in the Wolbachia PCR had a probability of $87 \%$ to be positive for I. hookeri as well. Likewise, a negative Wolbachia result predicted a negative $I$. hookeri PCR with a probability of $98 \%$. The association between PCR results for Wolbachia and I. hookeri DNA was statistically significant (p-value $<0.0001)$.

\section{Discussion}

DNA of I. hookeri was detected in ticks collected from locations broadly distributed across the Netherlands. Although this is the first notice of this species in the Netherlands the broad distribution and the cosmopolitan distribution of this insect indicates that the wasp is a native species. The prevalence varies strongly with sampling location as had been reported from other studies as well $[26,27]$. The prevalence might influenced by biological or climatic factors. Tick density, which in turn is affected by tick-host abundance, has been suspected to 


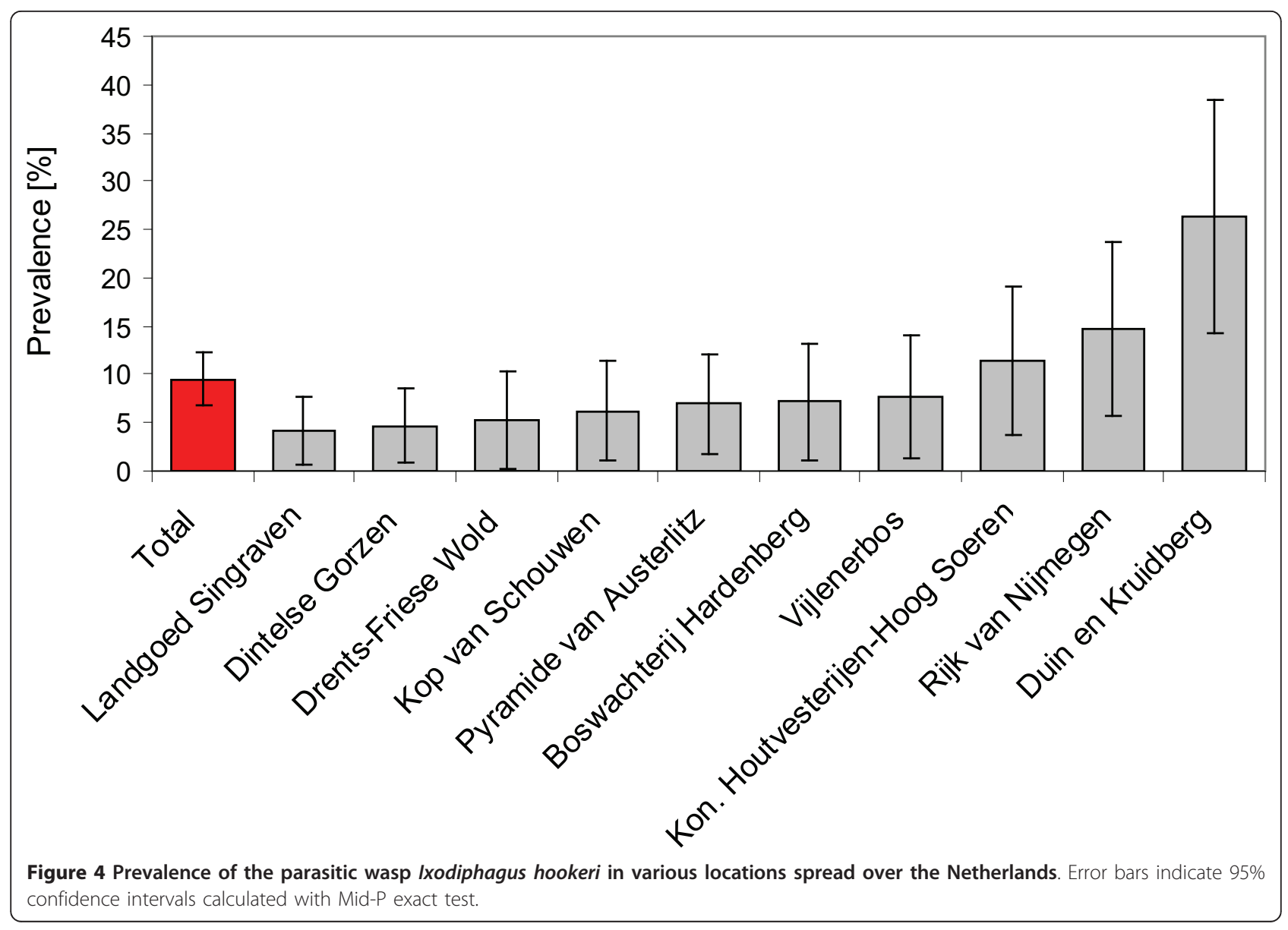

be a major determinant for the prevalence of I. hookeri [27]. This corresponds with the finding that the highest $I$. hookeri prevalence in this study was found in 'Duin \& Kruidberg' (Figure 4), an area with exceptional high tick density (data not shown). However, another area with comparable tick density, 'Kop van Schouwe', had a much lower I. hookeri prevalence. Other factors like (micro)climate, vegetation and prevalence of different vertebrate species in the habitats might play a role, but such data were not collected during this study.

The molecular data suggest that I. hookeri, as many other insects, may harbour at least one Wolbachia strain. The specimen studied here was infected with a Wolbachia strain similar to that of other Hymenoptera

Table 3 Association of Wolbachia wsp and I.hookeri $28 \mathrm{~S}$ rRNA PCR results

\begin{tabular}{|c|c|c|c|c|}
\hline & & \multicolumn{2}{|c|}{ Wolbachia PCR } & \\
\hline & & positive & negative & \\
\hline \multirow[t]{3}{*}{ I. hookeri PCR } & positive & 15 & 2 & 17 \\
\hline & negative & 2 & 124 & 128 \\
\hline & & 17 & 128 & 143 \\
\hline
\end{tabular}

but also closely matched Wolbachia endosymbionts of insects from different orders. Although the specimen hatched in our laboratory was apparently infected with a single strain, several $I$. hookeri positive ticks harboured multiple Wolbachia strains. Multiple infections with Wolbachia are known to occur in insects $[28,29]$ and the combination of these might have different biological impacts on their hosts. Wolbachia have been linked to parasitoid specialization [30] and different Wolbachia strains in $I$. hookeri might be one explanation for apparent differences in its biology in different countries $[18,19,31]$.

Detection of Wolbachia DNA in ticks in this study is strongly correlated with $I$. hookeri infestation. The small deviation between PCR results might be explained by different sensitivities of PCRs. On the one hand, some $I$. hookeri might have no or only a low Wolbachia load while others might have a high bacterial load. On the other hand, the copy number of the $28 \mathrm{~S}$ rRNA gene, which was used to detect $I$. hookeri in this study, is not known for this species and will influence the PCR sensitivity for this target. Furthermore PCR products from the prevalence study were not sequenced. Therefore, 
some of the wsp and $28 \mathrm{~S} r R N A$ positive PCR results might have been due to environmental contamination of samples with Wolbachia or insect species not related to infestation of ticks.

Data on spread and prevalence of I. hookeri around the world is scarce. The specificity of the I. hookeri PCR could be increased for future studies by the use of primers with high specificity, which can now be designed based on the 16S $r R N A$ and 28S $r R N A$ sequence data from this study. In future, molecular methods can be used to examine the spread and prevalence of $I$. hookeri in different tick species and regions.

\section{Conclusions}

We report for the first time the detection of $I$. hookeri in Dutch ticks and the presence of Wolbachia in I. hookeri. This is, to our knowledge, the first reported study investigating the prevalence of $I$. hookeri in tick populations with molecular methods. I. hookeri seems to harbour Wolbachia endosymbionts, which can explain previous reports of Wolbachia isolates from I. ricinus ticks. In case they are endosymbionts of parasitoids, and not of the ticks themselves, these Wolbachia are unlikely to play a role in human diseases.

\section{Acknowledgements}

The authors thank Roy Kleukers for his advice and inclusion of Ixodiphagus hookeri in the Dutch Species Catalogue. We are grateful for expert identification of the parasitic wasps by John Noyes, Natural History Museum, London.

\section{Author details}

${ }^{1}$ Laboratory for Zoonoses and Environmental Microbiology, National Institute for Public Health and Environment (RIVM), Bilthoven, The Netherlands. ${ }^{2}$ National Centre for Monitoring of Vectors (CMV), New Food and Consumer Product Safety Authority (nWWA), Dutch Ministry of Economic Affairs, Agriculture and Innovation, Wageningen, the Netherlands.

\section{Authors' contributions}

ETK performed laboratory analysis, analyzed data and wrote the first draft. $\mathrm{MB}$ coordinated wasp identification and contributed to the study design. EJS collected and provided ticks. HS contributed to the study design and wrote the final manuscript. All authors approved the final version of the manuscript.

\section{Competing interests}

The authors declare that they have no competing interests.

Received: 14 October 2011 Accepted: 7 December 2011 Published: 7 December 2011

\section{References}

1. Sassera D, Beninati T, Bandi C, Bouman EA, Sacchi L, Fabbi M, Lo N: 'Candidatus Midichloria mitochondrii', an endosymbiont of the tick Ixodes ricinus with a unique intramitochondrial lifestyle. Int J Syst Evol Microbiol 2006, 56:2535-2540.

2. Schouls LM, Van De Pol I, Rijpkema SG, Schot CS: Detection and identification of Ehrlichia, Borrelia burgdorferi sensu lato, and Bartonella species in Dutch Ixodes ricinus ticks. J Clin Microbiol 1999, 37:2215-2222.

3. Kawahara M, Rikihisa Y, Isogai E, Takahashi M, Misumi H, Suto C, Shibata S, Zhang C, Tsuji M: Ultrastructure and phylogenetic analysis of 'Candidatus Neoehrlichia mikurensis' in the family Anaplasmataceae, isolated from wild rats and found in Ixodes ovatus ticks. Int I Syst Evol Microbiol 2004, 54:1837-1843.

4. Fehr JS, Bloemberg GV, Ritter C, Hombach M, Luscher TF, Weber R, Keller PM: Septicemia caused by tick-borne bacterial pathogen Candidatus Neoehrlichia mikurensis. Emerg Infect Dis 2010, 16:1127-1129.

5. Pekova S, Vydra J, Kabickova H, Frankova S, Haugvicova R, Mazal O, Cmejla R, Hardekopf DW, Jancuskova T, Kozak T: Candidatus Neoehrlichia mikurensis infection identified in 2 hematooncologic patients: benefit of molecular techniques for rare pathogen detection. Diagn Microbiol Infect Dis 2011, 69:266-270.

6. von Loewenich FD, Geissdorfer W, Disque C, Matten J, Schett G, Sakka SG, Bogdan C: Detection of "Candidatus Neoehrlichia mikurensis" in two patients with severe febrile illnesses: evidence for a European sequence variant. J Clin Microbiol 2010, 48:2630-2635.

7. Welinder-Olsson C, Kjellin E, Vaht K, Jacobsson S, Wenneras C: First case of human "Candidatus Neoehrlichia mikurensis" infection in a febrile patient with chronic lymphocytic leukemia. J Clin Microbiol 2010, 48:1956-1959.

8. Tijsse-Klasen E, Fonville M, Gassner F, Nijhof AM, Hovius EK, Jongejan F, Takken W, Reimerink JR, Overgaauw PA, Sprong H: Absence of zoonotic Bartonella species in questing ticks: First detection of Bartonella clarridgeiae and Rickettsia felis in cat fleas in the Netherlands. Parasit Vectors 2011, 4:61.

9. Tijsse-Klasen $E$, Jacobs JJ, Swart A, Fonville M, Reimerink JH, Brandenburg AH, van der Giessen JW, Hofhuis A, Sprong H: Small risk of developing symptomatic tick-borne diseases following a tick bite in The Netherlands. Parasit Vectors 2011, 4:17.

10. Sarih M, M'Ghirbi Y, Bouattour A, Gern L, Baranton G, Postic D: Detection and identification of Ehrlichia spp. in ticks collected in Tunisia and Morocco. J Clin Microbiol 2005, 43:1127-1132.

11. van Overbeek $L$, Gassner F, van der Plas CL, Kastelein P, Nunes-da Rocha U, Takken W: Diversity of Ixodes ricinus tick-associated bacterial communities from different forests. FEMS Microbiol Ecol 2008, 66:72-84.

12. Wielinga PR, Gaasenbeek C, Fonville M, de Boer A, de Vries A, Dimmers W, Akkerhuis Op Jagers G, Schouls LM, Borgsteede F, van der Giessen JW: Longitudinal analysis of tick densities and Borrelia, Anaplasma, and Ehrlichia infections of Ixodes ricinus ticks in different habitat areas in The Netherlands. Appl Environ Microbiol 2006, 72:7594-7601.

13. Hartelt K, Oehme R, Frank H, Brockmann SO, Hassler D, Kimmig P: Pathogens and symbionts in ticks: prevalence of Anaplasma phagocytophilum (Ehrlichia sp.), Wolbachia sp., Rickettsia sp., and Babesia sp. in Southern Germany. Int J Med Microbiol 2004, 293(Suppl 37):86-92.

14. Saridaki A, Bourtzis K: Wolbachia: more than just a bug in insects genitals. Curr Opin Microbiol 2010, 13:67-72.

15. Breeuwer JA, Jacobs G: Wolbachia: intracellular manipulators of mite reproduction. Exp Appl Acarol 1996, 20:421-434.

16. Stouthamer R, Breeuwer JA, Hurst GD: Wolbachia pipientis: microbial manipulator of arthropod reproduction. Annu Rev Microbiol 1999, 53:71-102

17. Hu R, Hyland KE, Oliver JH: A review on the use of Ixodiphagus wasps (Hymenoptera: Encyrtidae) as natural enemies for the control of ticks (Acari: Ixodidae). Systematic and Applied Acarology 1998, 3:19-28.

18. Collatz J, Selzer P, Fuhrmann A, Oehme RM, Mackenstedt U, Kahl O, Steidle JLM: A hidden beneficial: Biology of the tick-wasp Ixodiphagus hookeri in Germany. Journal of Applied Entomology 2011, 135:351-358.

19. Takasu K, Nakamura S: Life history of the tick parasitoid Ixodiphagus hookeri (Hymenoptera: Encyrtidae) in Kenya. Biological Control 2008, 46:114-121.

20. Mwangi EN, Hassan SM, Kaaya GP, Essuman S: The impact of Ixodiphagus hookeri, a tick parasitoid, on Amblyomma variegatum (Acari: Ixodidae) in a field trial in Kenya. Exp Appl Acarol 1997, 21:117-126.

21. Jenkins A, Kristiansen BE, Allum AG, Aakre RK, Strand L, Kleveland EJ, van de Pol I, Schouls L: Borrelia burgdorferi sensu lato and Ehrlichia spp. in Ixodes ticks from southern Norway. J Clin Microbiol 2001, 39:3666-3671.

22. Tijsse-Klasen E, Fonville M, Reimerink JH, Spitzen-van der Sluijs A, Sprong $H$ : Role of sand lizards in the ecology of Lyme and other tick-borne diseases in the Netherlands. Parasit Vectors 2010, 3:42.

23. Zhou W, Rousset F, O'Neil S: Phylogeny and PCR-based classification of Wolbachia strains using wsp gene sequences. Proc Biol Sci 1998, 265:509-515. 
24. OpenEpi: Open Source Epidemiologic Statistics for Public Health. [http:// www.OpenEpi.com].

25. Gijswijt M: Tweede aanvulling op de naamlijst van de Nederlandse bronswespen (Hymenoptera: Chalcidoidea). Nederlandse Faunistische Mededelingen 2011, 35:33-35.

26. Hu R, Hyland KE, Mather TN: Occurrence and distribution in Rhode Island of Hunterellus hookeri (Hymenoptera: Encyrtidae), a wasp parasitoid of Ixodes dammini. J Med Entomol 1993, 30:277-280.

27. Stafford KC, Denicola AJ, Kilpatrick HJ: Reduced abundance of Ixodes scapularis (Acari: Ixodidae) and the tick parasitoid Ixodiphagus hookeri (Hymenoptera: Encyrtidae) with reduction of white-tailed deer. J Med Entomol 2003, 40:642-652.

28. Mouton L, Dedeine F, Henri H, Bouletreau M, Profizi N, Vavre F: Virulence, multiple infections and regulation of symbiotic population in the Wolbachia-Asobara tabida symbiosis. Genetics 2004, 168:181-189.

29. Reuter $M$, Keller L: High levels of multiple Wolbachia infection and recombination in the ant Formica exsecta. Mol Biol Evol 2003, 20:748-753.

30. Branca A, BP LER, Vavre F, Silvain JF, Dupas S: Intraspecific specialization of the generalist parasitoid Cotesia sesamiae revealed by polyDNAvirus polymorphism and associated with different Wolbachia infection. Mol Ecol 2011, 20:959-971.

31. Lyon SM, Van Driesche R, Edman JD: Ecology of Hunterellus hookeri (Hymenoptera: Encyrtidae) and Evaluation of Its Impact on Ixodes scapularis (Acari: Ixodidae) on Nonamesset Island in Massachusetts. Environmental Entomology 1998, 27:463-468.

32. Dowton M, Austin AD: Molecular phylogeny of the insect order Hymenoptera: apocritan relationships. Proc Natl Acad Sci USA 1994, 91:9911-9915.

33. Whitfield JB: Molecular and Morphological Data Suggest a Single Origin of the Polydnaviruses among Braconid Wasps. Naturwissenschaften 1997, 84:502-507.

34. Mardulyn P, Whitfield JB: Phylogenetic signal in the COI, $16 \mathrm{~S}$, and $28 \mathrm{~S}$ genes for inferring relationships among genera of Microgastrinae (Hymenoptera; Braconidae): evidence of a high diversification rate in this group of parasitoids. Mol Phylogenet Evol 1999, 12:282-294.

35. Owen AK, George J, Pinto JD, Heraty JM: A molecular phylogeny of the Trichogrammatidae (Hymenoptera: Chalcidoidea), with an evaluation of the utility of their male genitalia for higher level classification. Systematic Entomology 2007, 32:227-251.

doi:10.1186/1756-3305-4-228

Cite this article as: Tijsse-Klasen et al:: Parasites of vectors - Ixodiphagus hookeri and its Wolbachia symbionts in ticks in the Netherlands.

Parasites \& Vectors 2011 4:228.

\section{Submit your next manuscript to BioMed Central and take full advantage of:}

- Convenient online submission

- Thorough peer review

- No space constraints or color figure charges

- Immediate publication on acceptance

- Inclusion in PubMed, CAS, Scopus and Google Scholar

- Research which is freely available for redistribution 